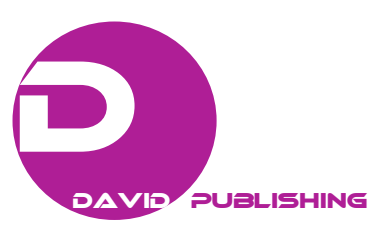

\title{
Extension of Giurgiu Port on Lower Danube
}

\author{
Radu-Constantin Cazamir \\ Structural Engineering and Technology Co. Ltd, Bucharest 021371, Romania
}

\begin{abstract}
The paper deals with the construction works devoted to extending and upgrading the port functions to the highest European Standards. The Port of Giurgiu is located on the left bank of the Danube River, at the $493 \mathrm{~km}$, and also at $65 \mathrm{~km}$ south of Bucharest, the Capital of Romania. Giurgiu is one of the Romanian largest Danubian Ports. Advanced computer programs were used in design. An active monitoring system, regarding the pre-existing constructions on the site, directly influenced by the excavations was also used. The adopted solutions for infrastructure were dependent by the monitoring results of construction site. The weak foundation conditions as well as the proximity of some existing buildings arouse unexpected obstacles difficult to overpass. However, by a perfect human cooperation all targets were finally reached.
\end{abstract}

Key words: Basin, cofferdam, Danube, dewatering, monitoring, mooring, tri-modal terminal.

\section{Introduction}

The port of Giurgiu located at river $493 \mathrm{~km}$ of the Danube, in the proximity of Bucharest and the Bulgarian port of Ruse, is a crossroad for flows and transshipment of freight between inland waterway, rail and road transport. Its infrastructure upgrade will contribute to enhancing the connections between different modes of transport allowing an increase of freight handled along the Romanian section of the Danube and the overall Rhine-Danube core network corridor. The navigable corridor starts from the port of Rotterdam to the North Sea, continues on Rhin, then on the canal between the German cities Bamberg on Main, the largest tributary of the Rhine, and the Kelheim on the Danube, which leads to the port of Constanta. The 3,100 km waterway runs across the Netherlands, Germany, Austria, the Czech Republic and Slovakia, Hungary, Serbia, Bulgaria and Romania (Fig. 1).

The tri-modal transport terminal aims to create a transport infrastructure within Giurgiu harbor area, which will generate the increase and efficiency of the

Corresponding author: Radu-Constantin Cazamir, UNESCO Chair \# 177, expert member ICOMOS/Iscarsah, research fields: cultural heritage, seismic engineering, coastal and offshore structures. commercial freight traffic through the connection of the shipping, railway and road transport routes. This is expected to increase the importance of Giurgiu port in the freight transport system, to attract new customers, trade markets, as well as new products and services; it is also proposed to increase services to regional markets such as Bulgaria and Turkey.

The tri-modal terminal will be the largest building on the site, with an area of approximately $8,000 \mathrm{sqm}$ $(200 \times 40 \mathrm{~m})$ and a height of approximately $16.5 \mathrm{~m}$. This terminal will be provided with a metallic structure and the walls may be by metal panels filled with polyurethane foam. Inside the terminal will be allowed the inland waterway access by means of a mooring basin, railroad by means of the industrial railway and the road for trucks, in order to transfer the goods between the three types of means of transport. In the south-west of the tri-modal terminal will be arranged a navigable basin $100 \mathrm{~m} \times 15 \mathrm{~m}$ with a depth of $13 \mathrm{~m}$. The navigable basin will allow the access of self-propelled ships and barges to their loading/unloading area. The infrastructure of the hall will be made of indirect foundation system, a network of drilled piles, and a network of foundation beams resting on the heads of these piles. The barge docking basin is an integral part of the infrastructure of the terminal 


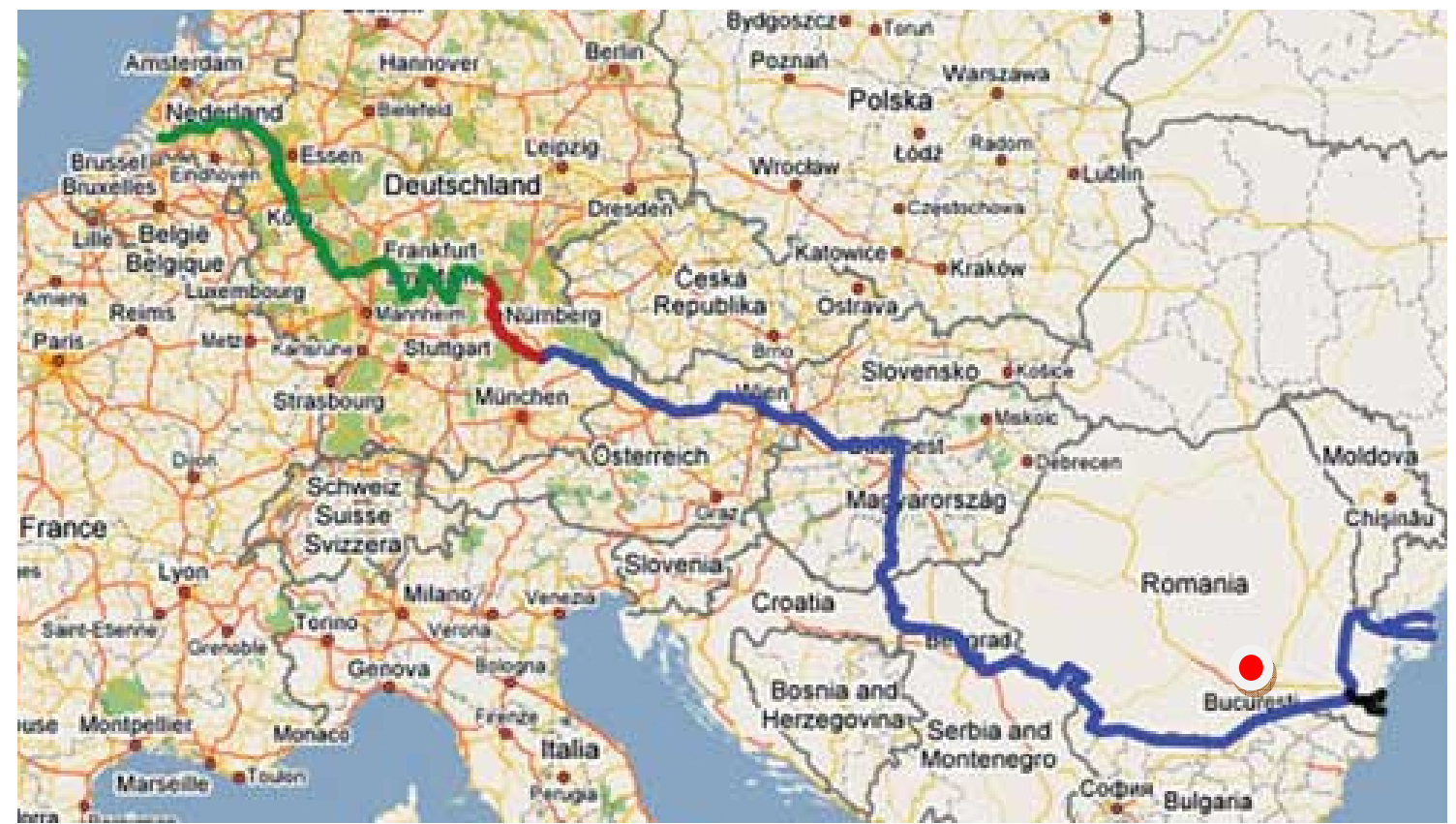

Fig. 1 Rhine-Danube core network.

warehouse and for the realization of the basin will be made of reinforced concrete walls based on a network of drilled piles. From the site provided, the structure of the old ferryboat connecting Giurgiu and Ruse had to be demolished [1].

\section{Site Investigation}

\subsection{Geotechnical Lithology, Indicates the Following Stratification}

- Filling-sandy loam to loamy sand, gravel, tamping average; the layer has a variable thickness, between 3.60-4.70 m;

- Weakly cohesive layer of low consistency-silty clay; this layer is found in the three geotechnical drillings up to the depths of 6.00-7.00 m, starting from the bottom of the filling;

- Weakly cohesive layer cohesive fine-fine gray sand, having a thickness of about $14.00 \mathrm{~m}-12.50$;

- Rock-organogenic limestone, altered and cracks at the upper side by about $50-100 \mathrm{~cm}$ broken starts from a depth of $14 \mathrm{~m}$.

The work was classified as in geotechnical category no. 3, which imposed a complex approach also from geotechnical investigation, as from design point of view. The execution was permanently monitored and the measurements were compared with the calculations, allowing a rapid intervention if the real behavior would be different from the estimated one [2].

\subsection{Water Levels}

Because of the geographic location on the continent of the Danube river basin, the contact between the temperate-oceanic climate in the west, temperate-continental in the east and the Baltic influences in the north, the hydrological regime of the Danube is characterized by the existence of significant level and flow variations in the course of the year and over time. Large waters occur in spring as a result of melting snow and heavy rains, but in the upper and middle course, take place in March-April, and in the lower, in May, water levels that may fluctuate about $10 \mathrm{~m}$ depending on the season (Fig. 2).

\section{Cofferdam}

Cofferdam is designed for the dewatering the work area necessary for demolition the old ferry structure and for the realization of the infrastructure of mooring 
basin, warehouse, platform and access road. A large cofferdam made from steel sheet piles will be used for a period of time of about 1-2 years. After completion of the infrastructure works, it will be eliminated by excavating the fillings and extracting the steel sheet piles (Fig. 3).

For a more accurate assessment of the efforts in the design structure, modeling was used in numerical computing programs. The method of calculation takes into account the elastic properties of the materials used and the elastoplastic properties of the land. Also, friction conditions are provided on the surface structure interaction surfaces. The varying depth of the land and variable water pressure according to the section considered were taken into account (Fig. 5).

The Cofferdam, as a temporary structure, is composed of:

- Steel sheet piles wall in front of the work area. The height of steel sheet piles will be about $21 \mathrm{~m}$, will be over the level of $19.06 \mathrm{mMNS}$ which corresponds to the probability of overtaking of $10 \%$. The length of the steel sheet piles wall will be of approx. $90 \mathrm{~m}$. The profile of these sheet piles is GU $22 \mathrm{~N}$, with an elastic modulus of section $\mathrm{Wy}=2,200 \mathrm{~cm}^{3} / \mathrm{m}$ (Figs. 4 and 6).

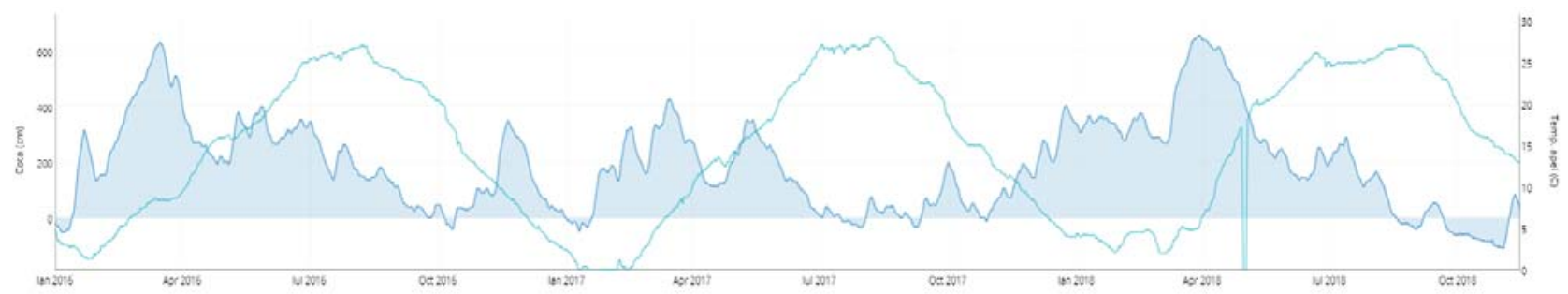

Fig. 2 Variations of water levels in Danube River in Giurgiu at local temperatures.
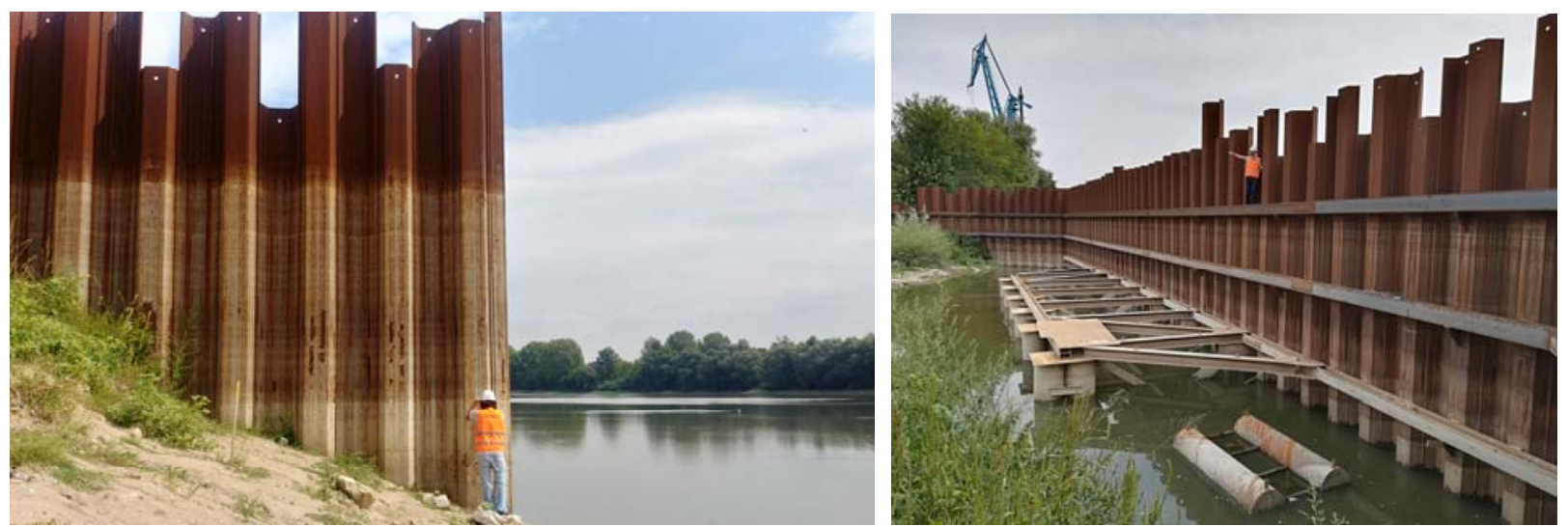

Fig. 3 Cofferdam from steel sheet piles GU 22N, one can observe the variation of the water levels.

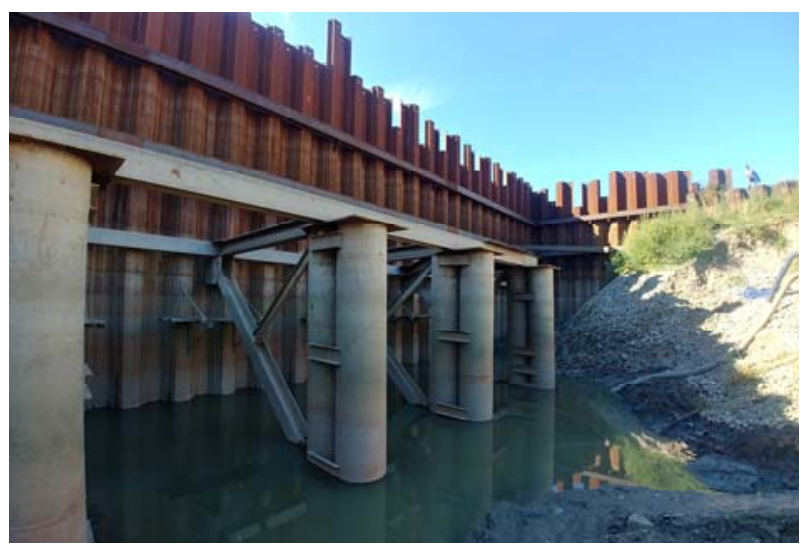

Fig. 4 Supporting system. 


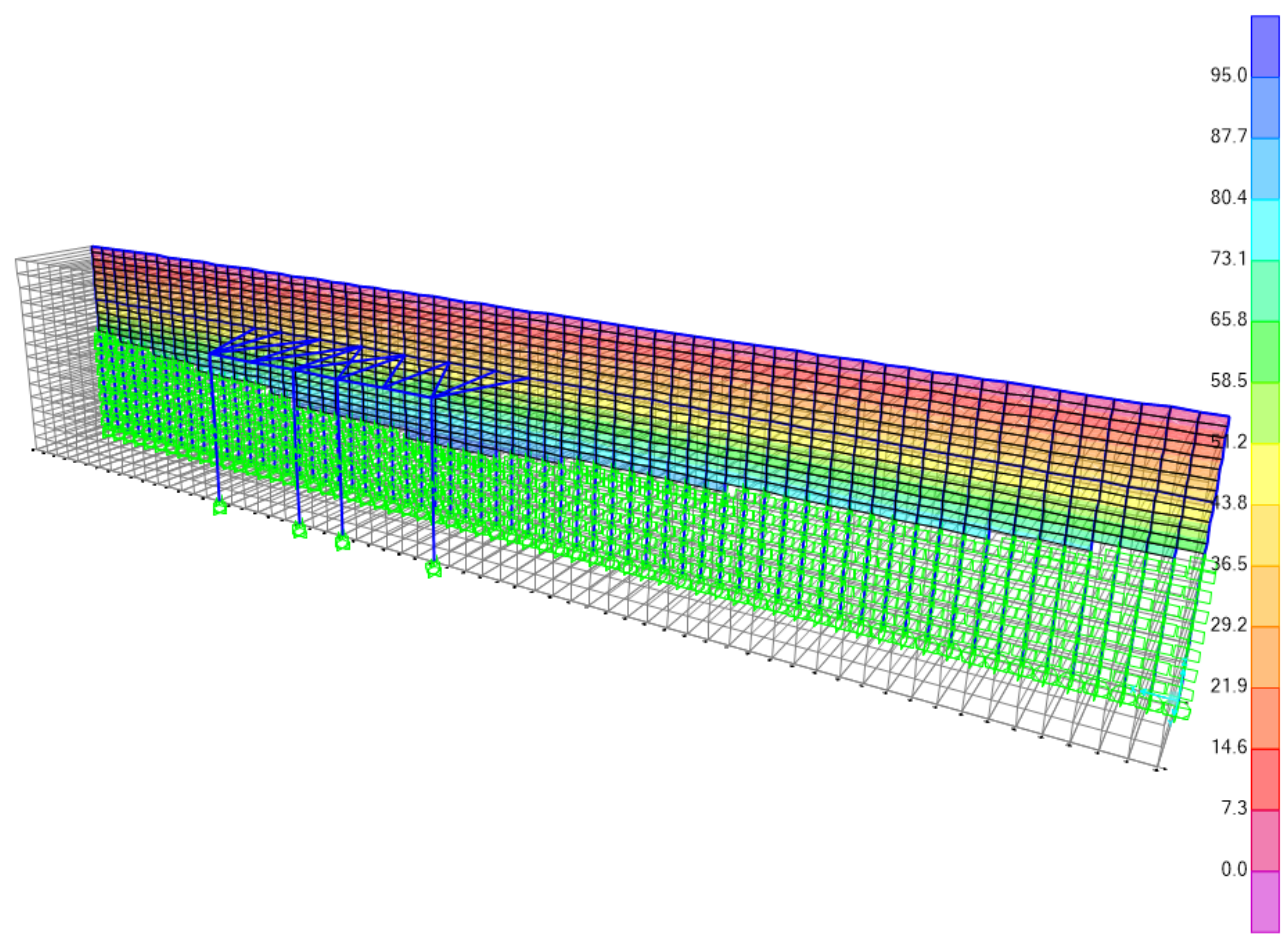

Fig. 5 Calculation of cofferdam.

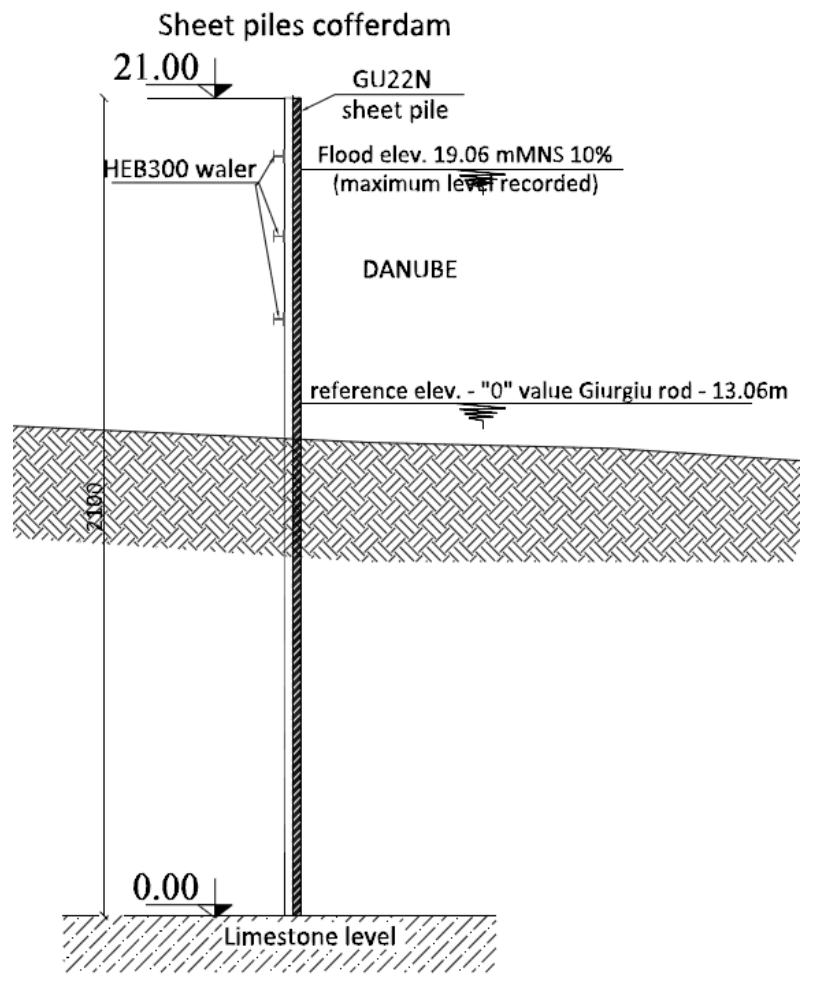

Fig. 6 Section of cofferdam.

- Supporting system consisting of pipes Ø 813-7.1 $\mathrm{mm}$ and HEB300 beams, which will ensure the overall stability of the sheet piles wall. In front of the unfavorable section, a metal support system will be made HEB300, trapezoidal beam with its dimensions of $\mathrm{h}=5.75 \mathrm{~m}, \mathrm{~B}=28.00 \mathrm{~m}$ and $\mathrm{b}=20.00 \mathrm{~m}$. It will be 
mounted at $15.35 \mathrm{mMNS}$ and will be supported on 6 pillars made of two pipes $\varnothing 813-7.1 \mathrm{~mm}$, solidarized and filled with ballast, according to Euro code 7 . The pillars will have a depth of $10 \mathrm{~m} \mathrm{[3].}$

\section{Demolition Works}

This project started by demolishing the existing structures on the ground, that is, by demolishing the old ferryboat structures that was built between 1940-1941 (Fig. 7).

During the demolition of the ferryboat structure, it is found that the foundation of the columns is at a much lower level than expected. Continuing demolition work and making deep excavations in the terrain that is so sensitive leads to cracks in the adjacent slopes (Fig. 8).

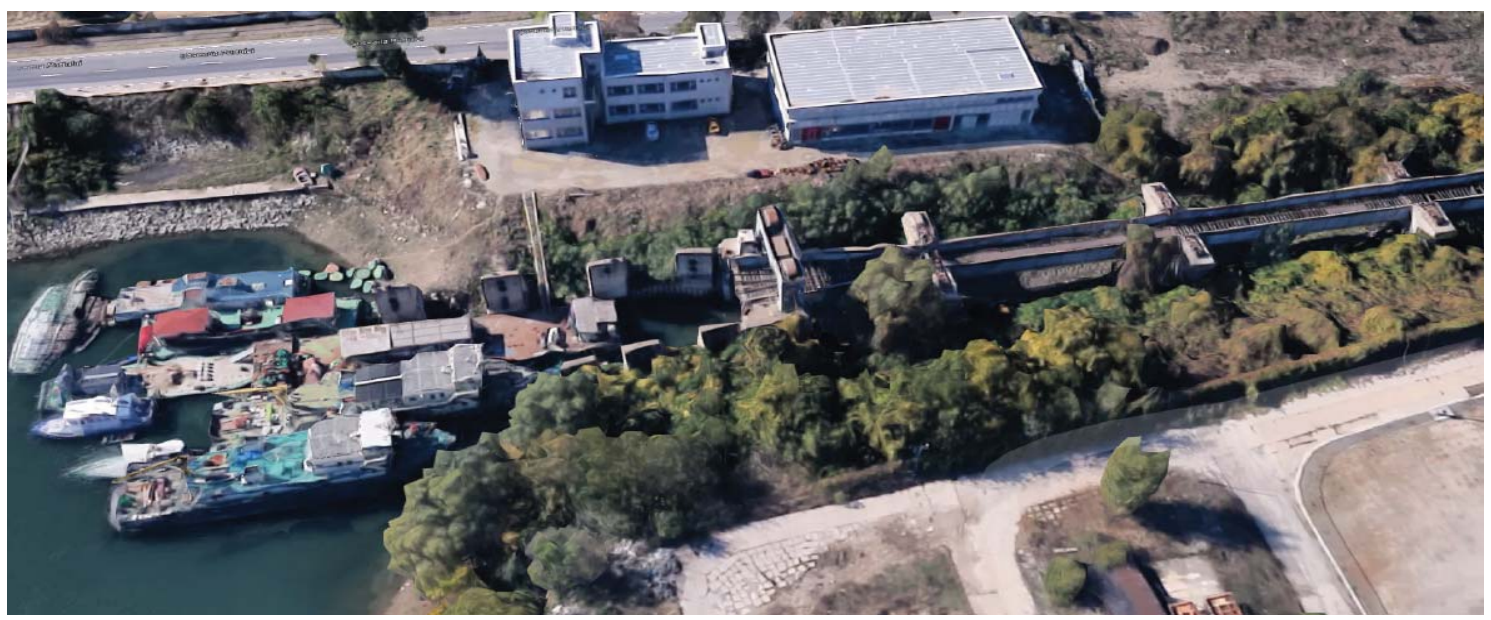

Fig. 7 Ferryboat structure built between 1940-1941 and demolished in 2017.

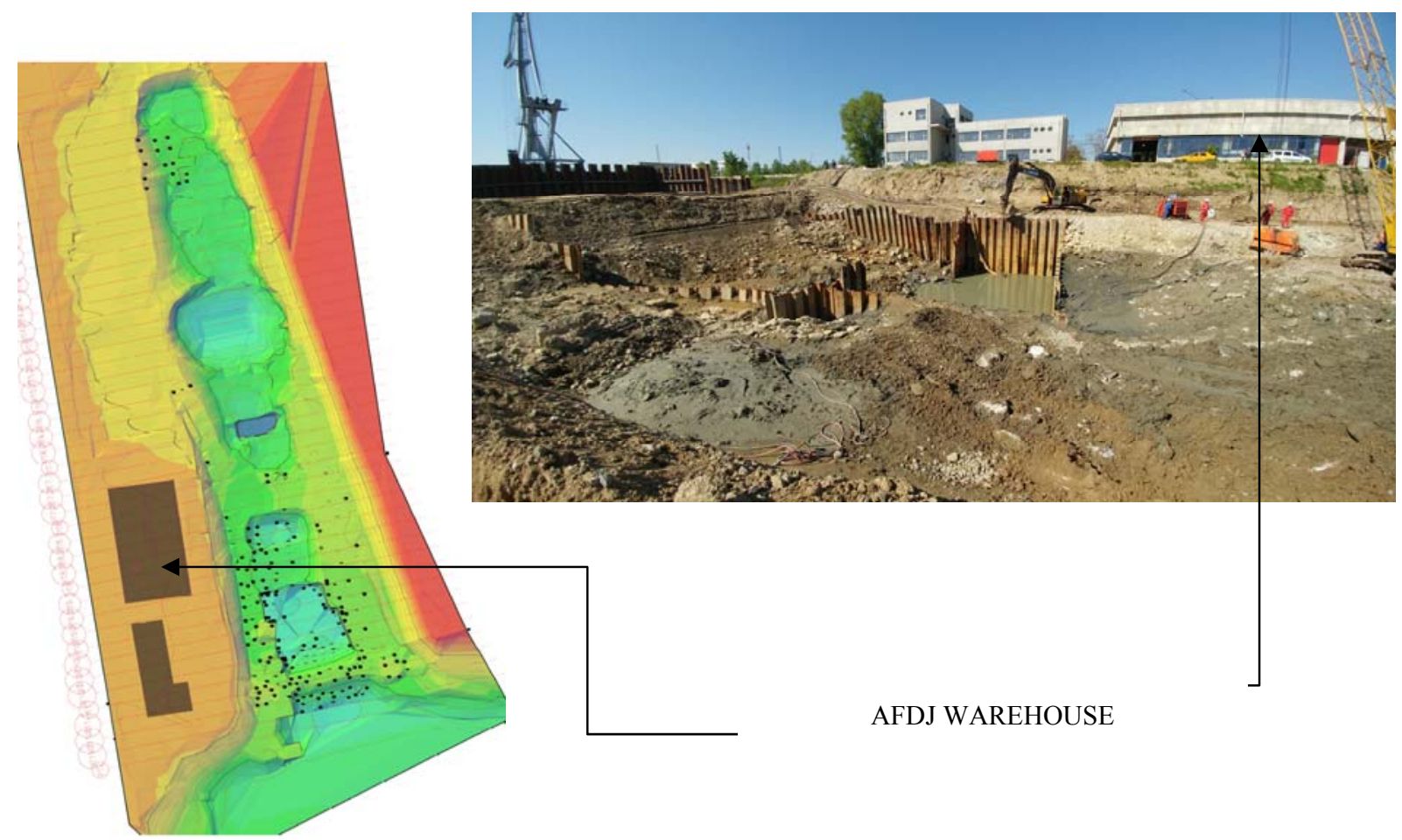

Fig. 8 Topographic survey and the proximity of the AFDJ warehouse to the excavation, one can observe the existing sheet piles which were around the ferryboat bridge columns. 
After the demolition of the vertical elements supporting the ferry bridge, a topographic survey is made and the possibility of continuing the demolition works as foreseen is re-analyzed.

Following the analysis, there is a result that the monitoring of the adjacent buildings and a project to secure the slope on the west side near to the AFDJ warehouse were needed.

4.1 Monitoring the Construction in the Area of Influence of the Excavation

4.1.1 Monitoring the Vertical Deformations of the Building by Topographical Methods

As a result of the data obtained, vertical deformation tendencies of the building and the massive soil were identified, summarized in the Fig. 9. The minimum, maximum and average values recorded for each reading are shown in Table 1.

4.1.2 Monitoring the Deformation of the Massive Earth: The Inclinometric Method

In order to determine the horizontal displacements of the foundation terrain of the existing structures, three inclinometers have been installed, with a depth of $20 \mathrm{~m}$ up to the limestone layer (Fig. 10).

As a result of the data processing, it can be observed that the slope continues to move in the area at the corner of the building at a rate of about 2.5 $\mathrm{mm} / \mathrm{month}$

4.2 Modeling the Triggering of the Instability Phenomenon, the Slope on the West Side near the AFDJ Warehouse

The numerical model was made using the Finite Element Method, in the plane of deformations, and from the point of view of the material laws, the Mohr-Coulomb elastoplastic linear elastoplastic models were considered for earthy and linear elastic for the base rock (Fig. 11).

From the point of view of the development of the plastic zones, they created a yielding surface starting from the foundation of ADFJ warehouse and continuing to the top of the existing sheet piles. It can be noticed that the upper limit of the plastic zones ("tension cut-off points" in Fig. 12) coincides with the position of the cracks that appeared.

Following the analysis of the results, the following can be concluded:

- Factors favoring instability are related to sensitivity soil, both lithological and due to deficiencies of the foundation system of the AFDJ warehouse.

- Slope failure was due to the excavation without retaining system and from a faulty system to achieve the dewatering of the excavation for the demolition of

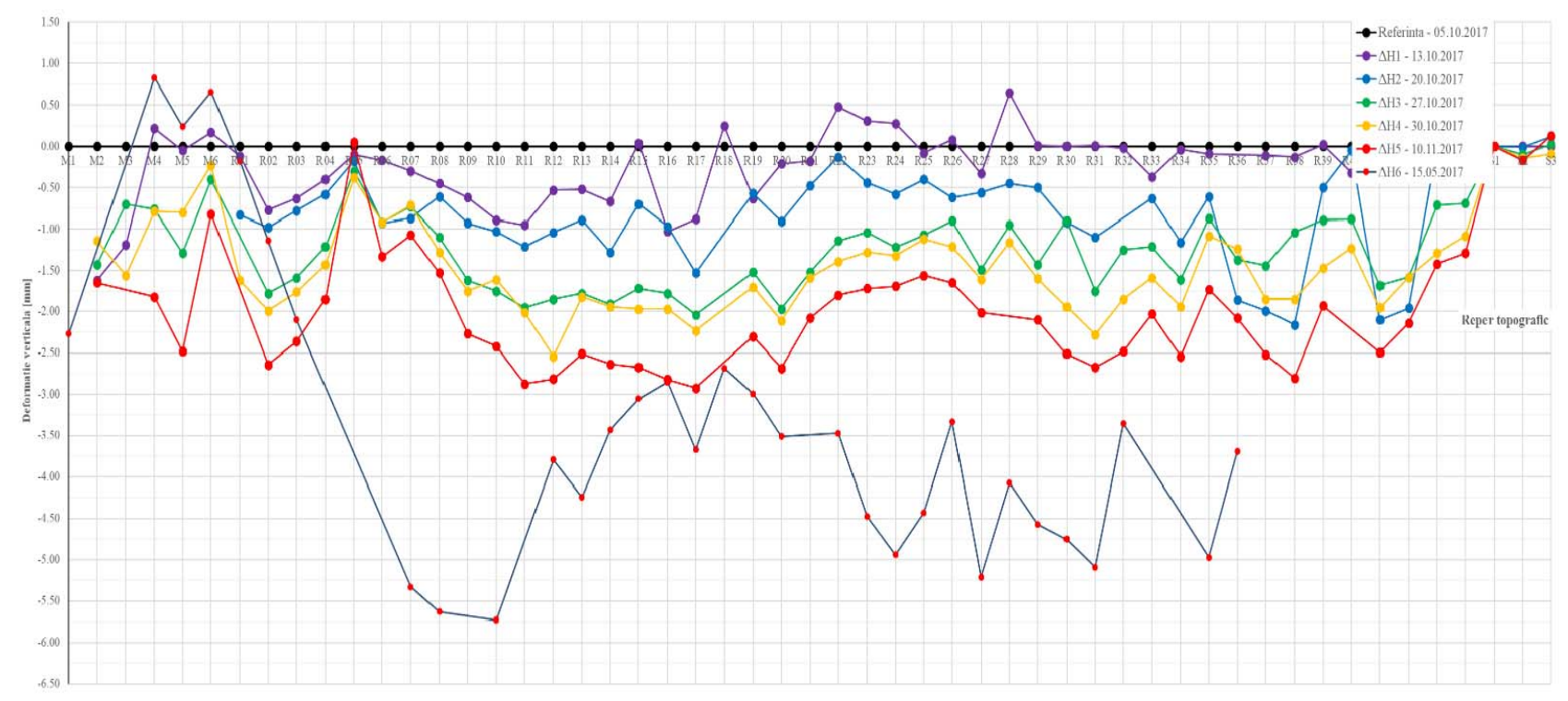




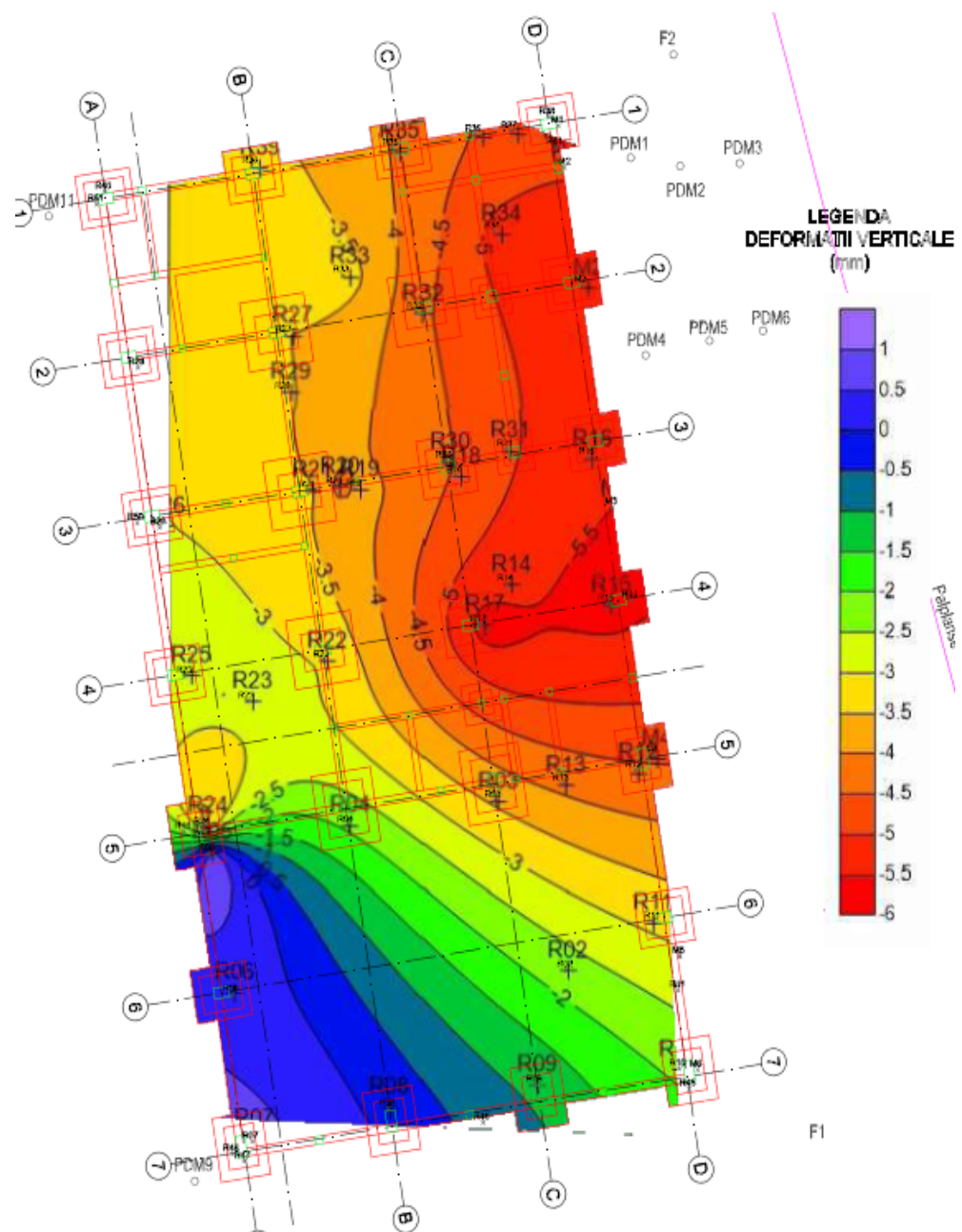

Fig. 9 Monitoring of the settlements recorded for the AFDJ building by topographical methods.

Table 1 Centralized table of extreme values determined by topographical method.

\begin{tabular}{llll}
\hline Reading & Minimum value $[\mathrm{mm}]$ & Medium value $[\mathrm{mm}]$ & Maximum value $[\mathrm{mm}]$ \\
\hline Reading 1-13.10.2017 & -1.62 & -0.25 & 0.65 \\
Reading 2-20.10.2017 & -2.16 & -0.80 & 0.12 \\
Reading 3-27.10.2017 & -2.04 & -1.22 & 0.03 \\
Reading 4-30.10.2017 & -2.54 & -1.43 & 0.00 \\
Reading 5-10.11.2017 & -2.92 & -1.95 & 0.13 \\
Reading 6-16.05.2018 & -5.73 & -3.35 & 0.83 \\
\hline
\end{tabular}



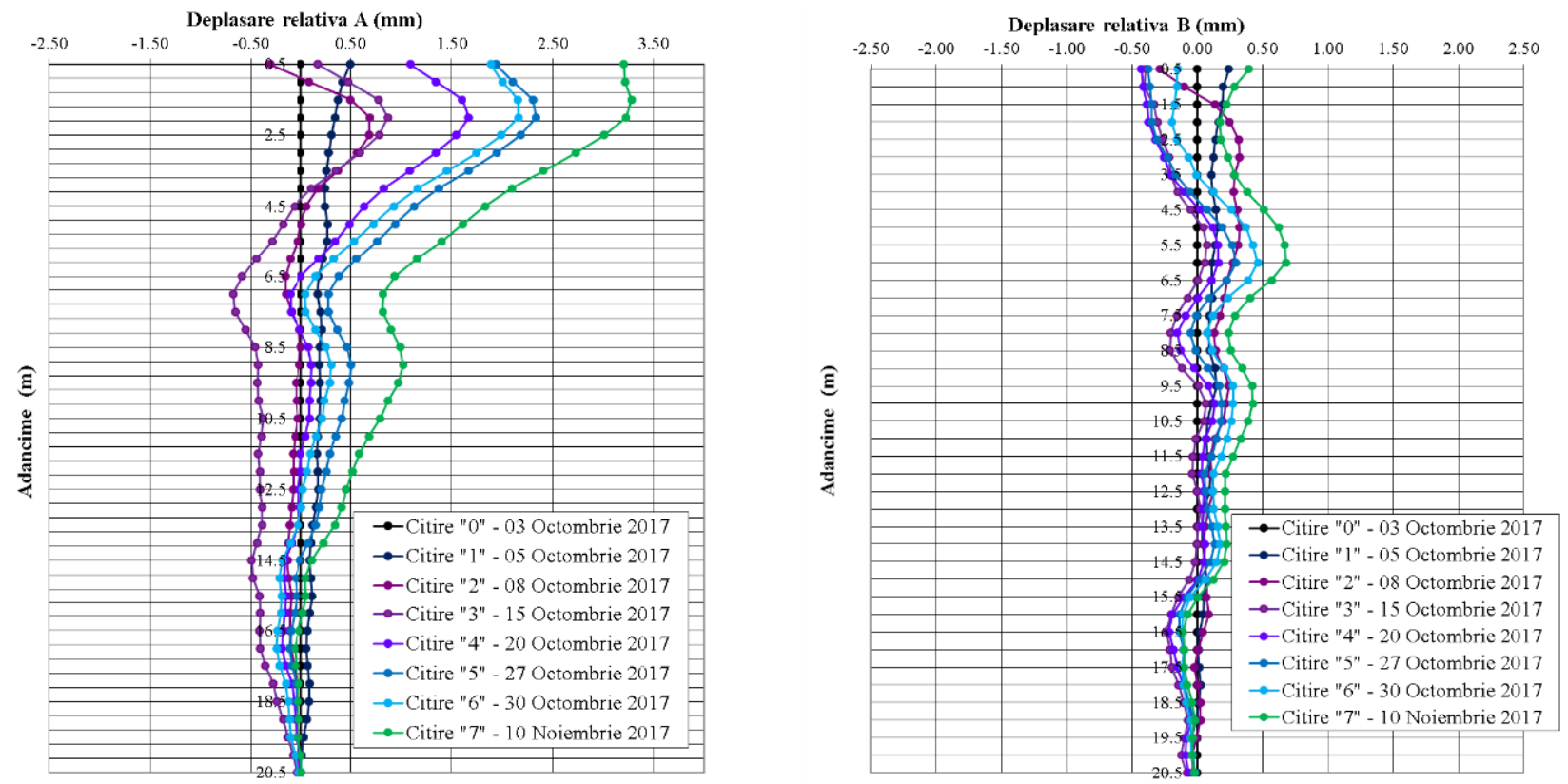

Fig. 10 Inclinometer measurements, located at the corner of the ADFJ building.

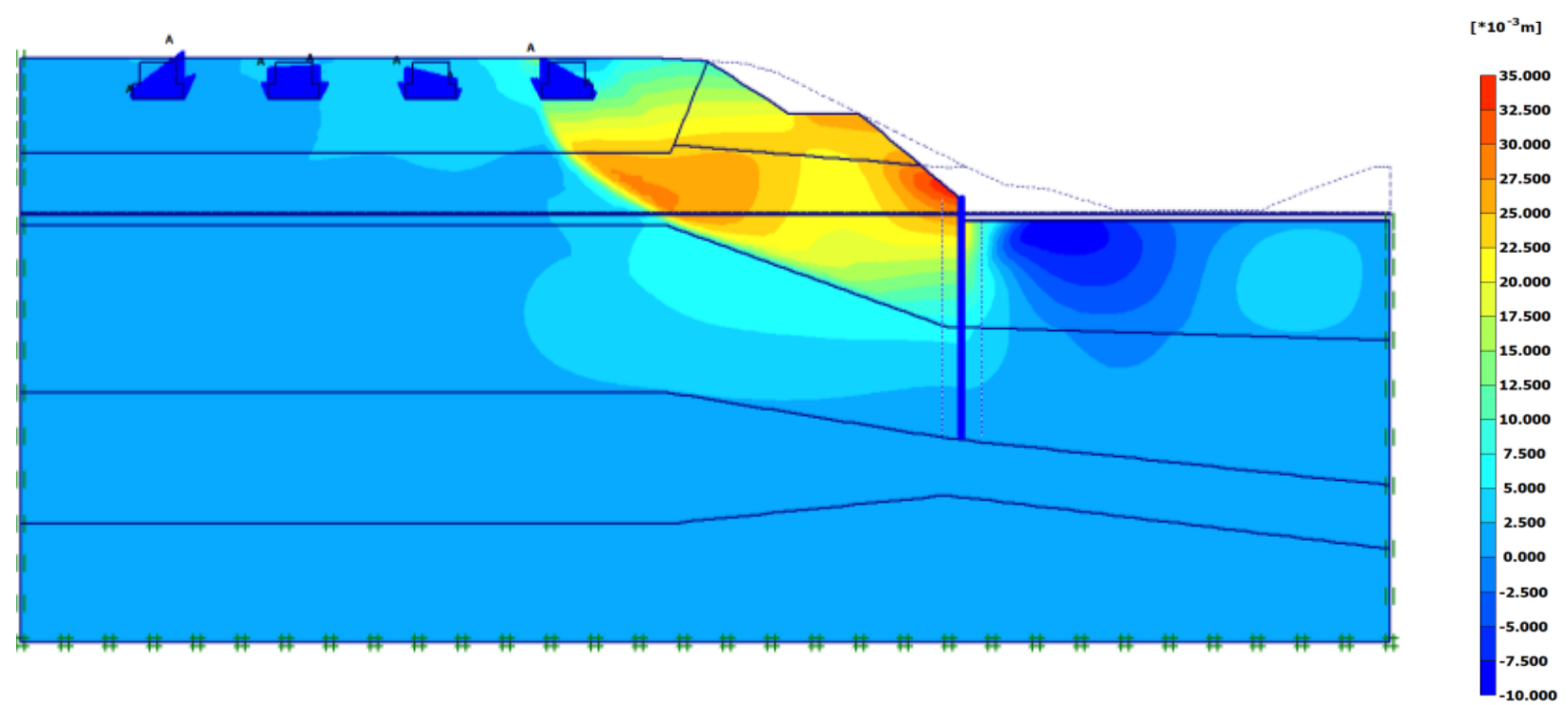

Fig. 11 Horizontal displacements of the slope intron of AFDJ warehouse, it can see the formation of sliding surface.
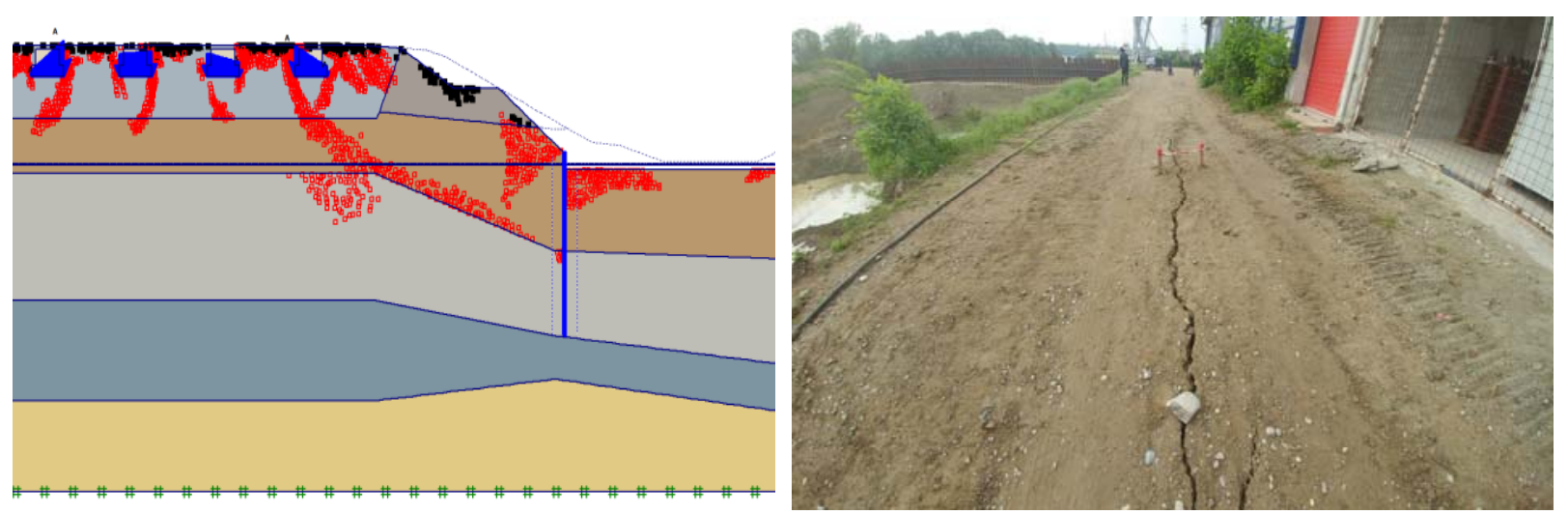

Fig. 12 Slope instability phenomenon, plastic points in the soil and the cracks along the slope. 

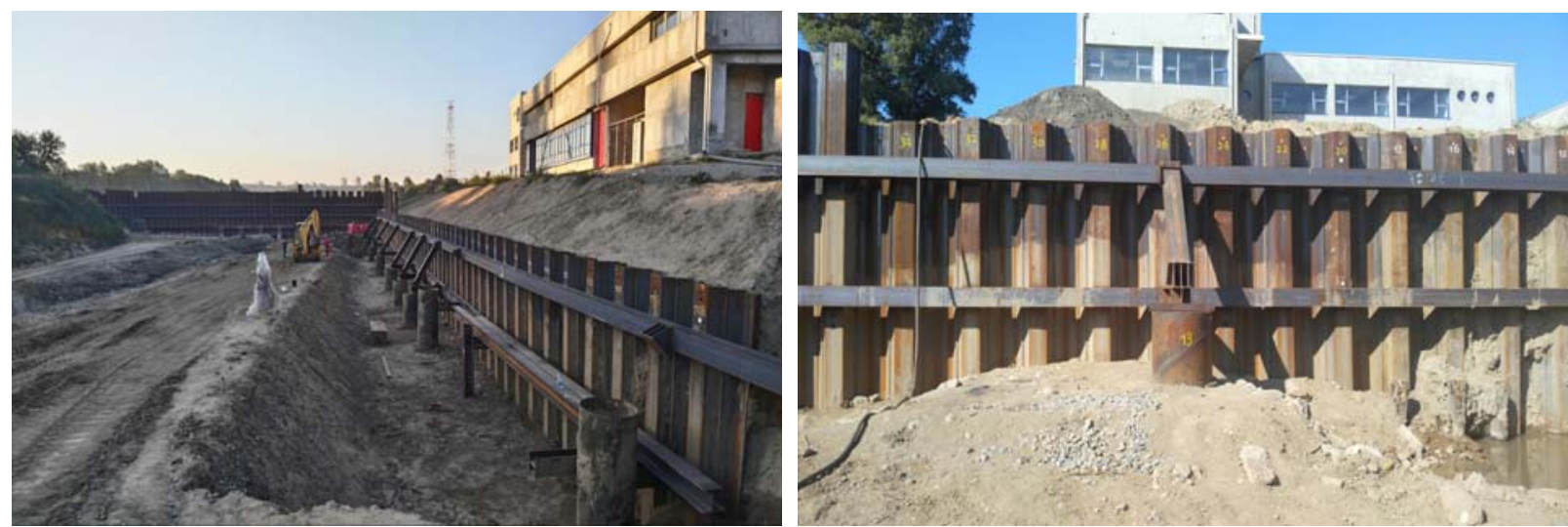

Fig. 13 Retaining structure on the side of the AFDJ neighborhood.

Table 2 The characteristic values of the earth's mechanical parameters considered in the calculation.

\begin{tabular}{lllll}
\hline Layer & $\gamma_{\mathrm{k}}$ & $\mathrm{E}_{\mathrm{k}}$ & $\varphi_{\mathrm{k}}^{\prime}$ & $\mathrm{c}_{\mathrm{k}}^{\prime}$ \\
& {$\left[\mathrm{kN} / \mathrm{m}^{3}\right]$} & {$[\mathrm{kPa}]$} & {$[\mathrm{kPa}]$} & {$[\mathrm{kPa}]$} \\
\hline Filling & 18.50 & 12,500 & 30.00 & 5.00 \\
Sandy clayey & 19.00 & 6,500 & 27.00 & 10.00 \\
Sand-fine & 19.50 & 10,000 & 32.00 & 1.00 \\
Sand medium & 20.50 & 25,000 & 34.00 & 1.00 \\
\hline
\end{tabular}

the pillars, which includes the use of high-flow pumps that washed the fine material under the AFDJ warehouse.

\subsection{The Technical Project for the Safety of the Slope after the Instability Phenomenon}

In view of the cofferdam from steel sheet piles made for the closure of the working area, it is natural that the required retaining structure on the side of the AFDJ neighborhood should be achieved also from steel sheet piles. They were designed with a length sufficient to obtain a sufficient hydraulic gradient to prevent water from flowing under the screen. The solutions are to support the new wall of steel sheet piles through counter-benches and additional supporting metal structures. After the calculations, a $16 \mathrm{~m}$ long GU $16 \mathrm{~N}$ steel sheet piles were selected.

Calculations were performed using the finite element method considering the plane state of deformation. The earth was modeled using the Mohr-Coulomb elastoplastic criterion. The parameters considered, based on the in-situ and laboratory tests, are found in Table 2.

Diaphragm wall calculation was done based on Eurocode 7 (SR EN 1997-1:2004 and the Romanian
National Annex SR EN 1997-1/NB). According to the National Annex in Romania, the calculations were performed for design approaches 1 and 3, approach 2 not being recommended by this document. As well, according to the Romanian technical norm for retaining structures (NP 124-2010), the seismic action was considered on the wall. The seismic coefficient was decreased considering the temporary character of the retaining structure, according to the same technical norm (Fig. 14).

After realization of the retaining wall, and the implementation of the support solutions, the monitorization showed that the settlement and deformations of the neighboring building were stopped, so it is possible to proceed to the next stage of implementation of the general project: mooring basin and the tri-modal terminal [4].

\subsection{Other Risk Associated with Excavations in the Old Port Area}

In the Second World War, Giurgiu was Romania's first oil harbor on the Danube, and the target of five air raids from the Anglo-American aviation between 2 June and 3 July 1944. 

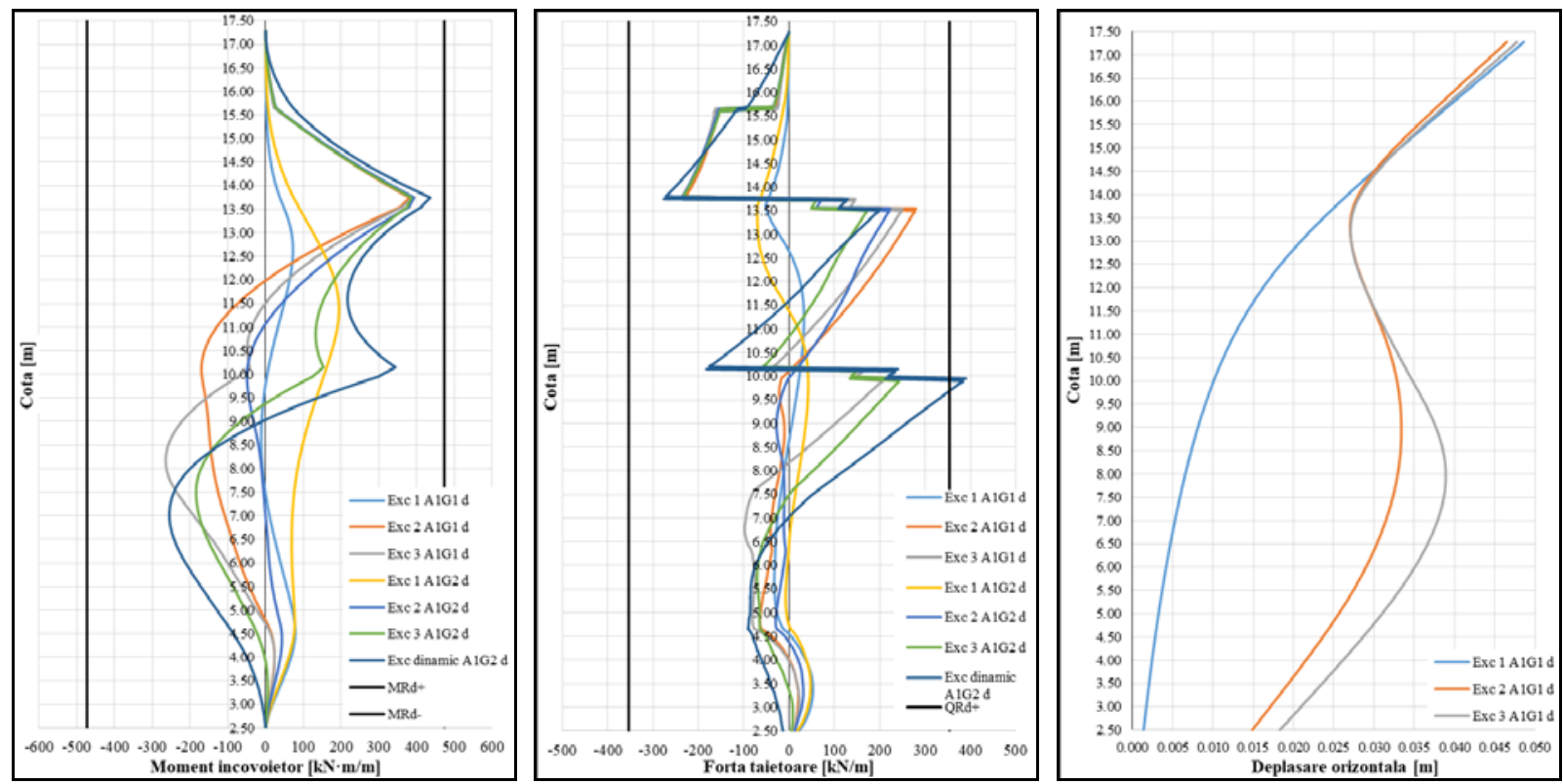

Fig. 14 Bending moment, shear force in the diaphragm wall and horizontal displacements of the sheet piles wall for technological stages.

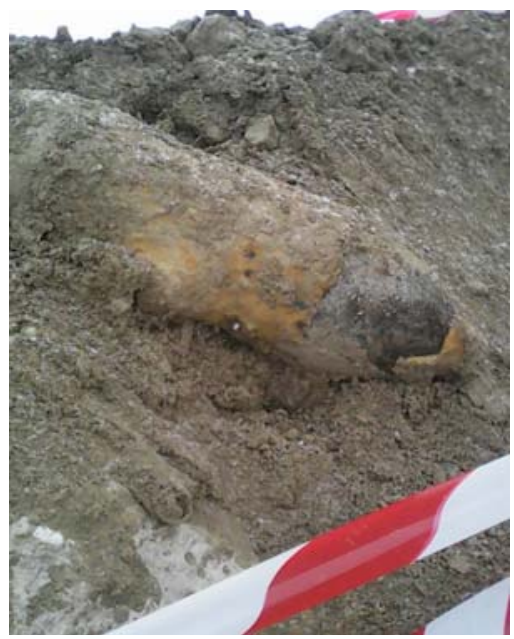

Fig. 15 Aviation bomb from WWII found on site.

Due to these facts in time of the excavations an unexploded aviation bomb of $250 \mathrm{~kg}$ was found inside the digging ground. The pyrotechnics and firefighters immediately came and secured the area, evacuating the personal from the work site.

\section{High Performance Green Port Giurgiu}

The objective of the present documentation is the presentation of the design for the construction of the mooring basin, as well as the structural role of the secant pile walls in the construction of the mooring basin and for tri-modal terminal (Figs. 16 and 17). The projected infrastructure is a complex one made up of indirect foundations (a network of drilled piles with a recoverable casing) and a network of foundation beams resting on the piles heads by means of reinforced concrete caps. The floor of the building will be reinforced concrete slab based on reinforced concrete piles.

Consideration has been given to a number of existing overloads on site, or that will exist with the putting into use of the investment object.

Continuous AFDJ building foundations: $60 \mathrm{kPa}$, were considered as punctual loads.

Overload in road transport (left side of the mooring basin): $25 \mathrm{kPa}$ was considered a uniformly distributed load.

The overload load on the platform of the trimmed hall (right side of the mooring basin): $250 \mathrm{kPa}$ was considered uniformly distributed load.

The displacements resulting for the piles head are:

- Left side wall: $25.53 \mathrm{~mm}$;

- Wall on the right: $52.60 \mathrm{~mm}$.

The displacements resulting for the upper part of the $80 \mathrm{~cm}$ basin walls are: 


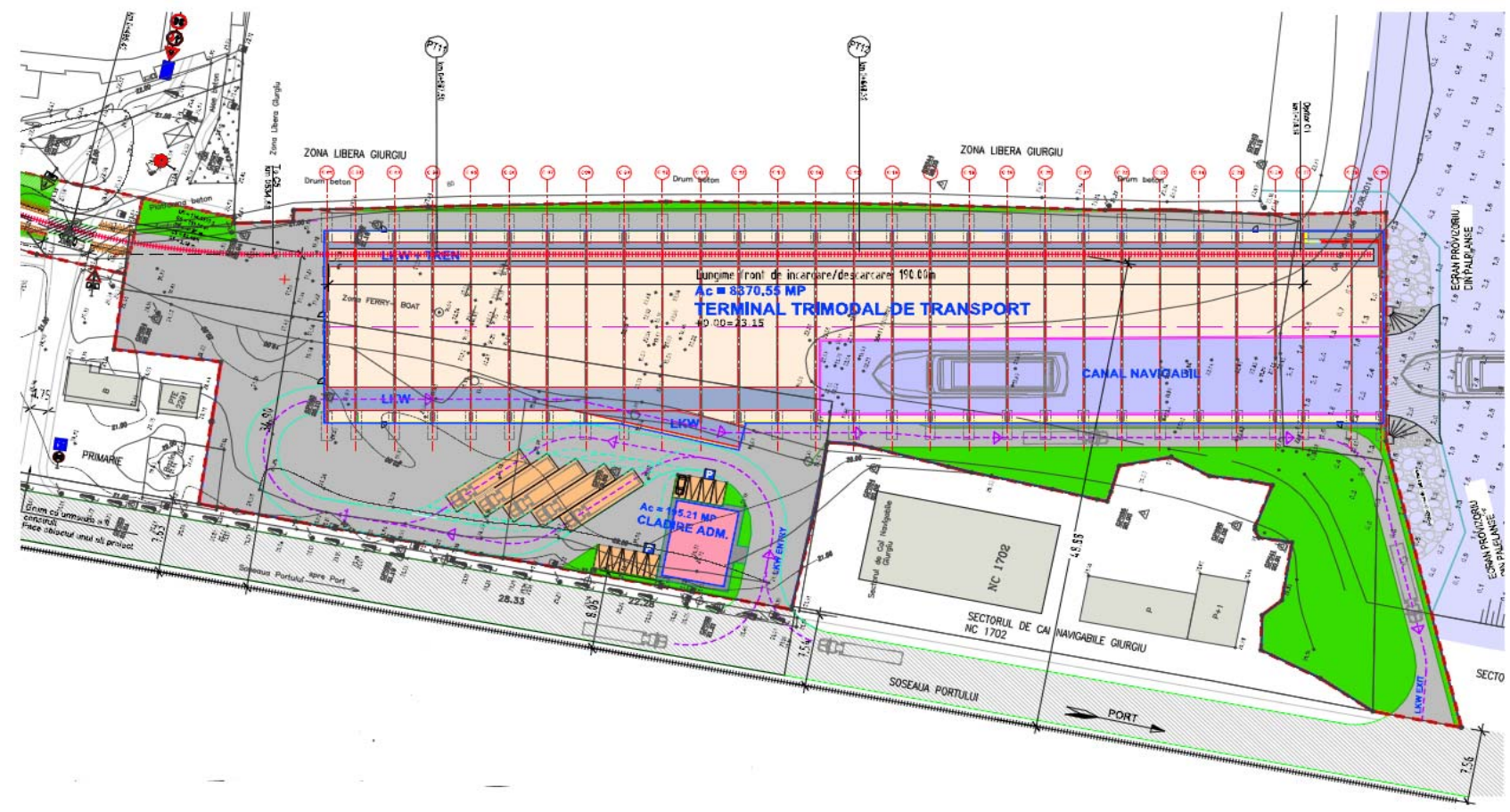

Fig. 16 3D model of trimodal terminal, plan of the terminal.

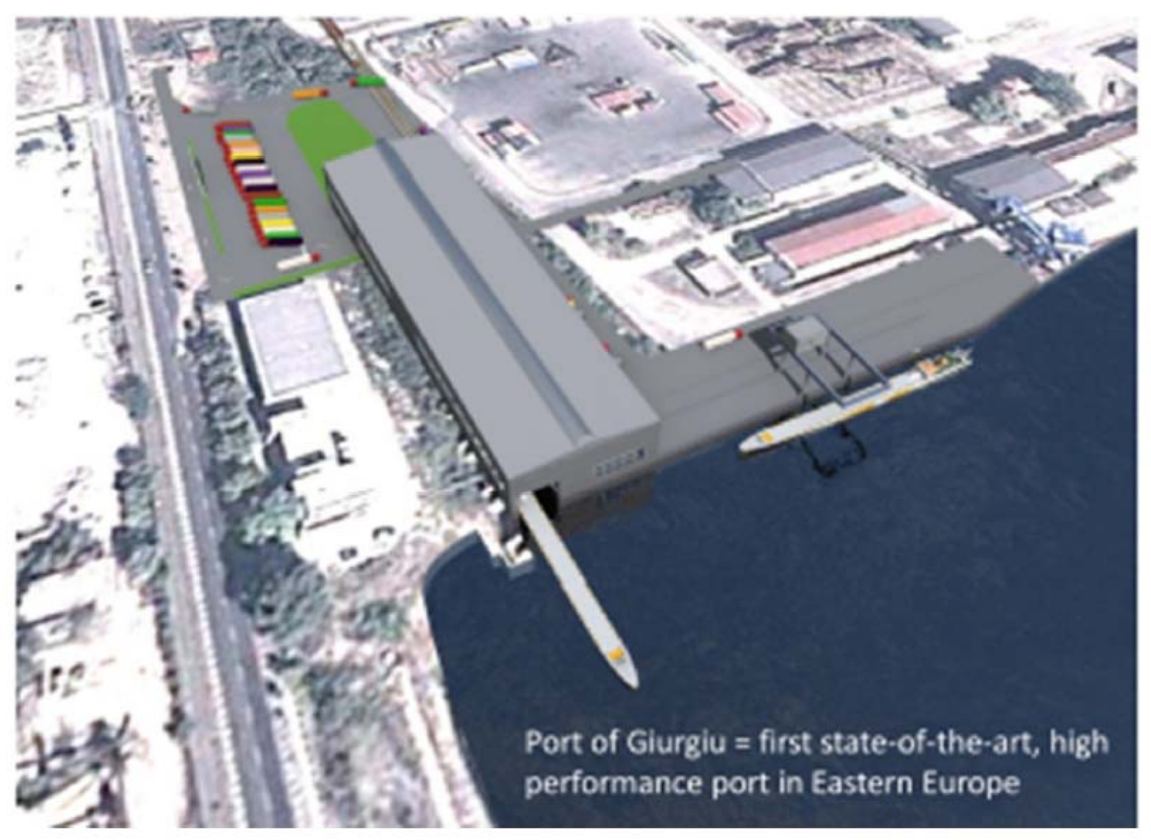




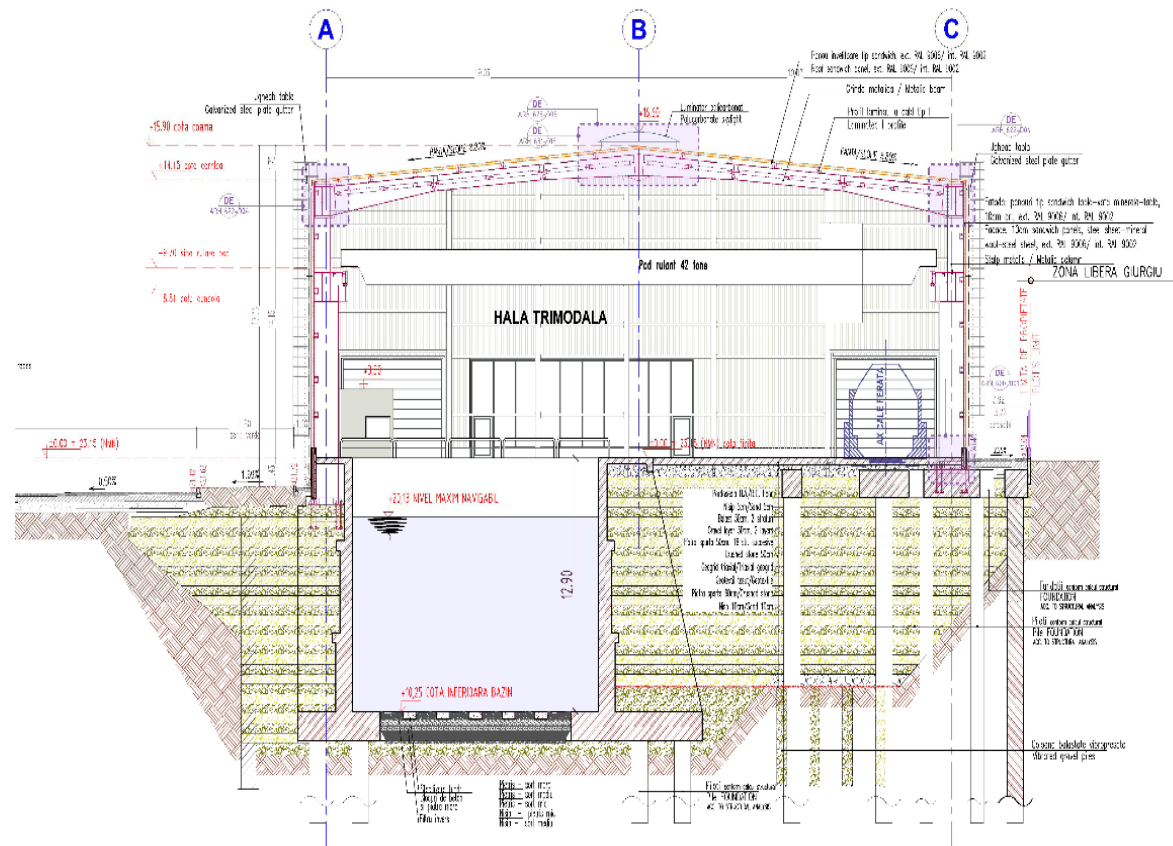

Fig. 17 3D model of trimodal terminal and section of the terminal.

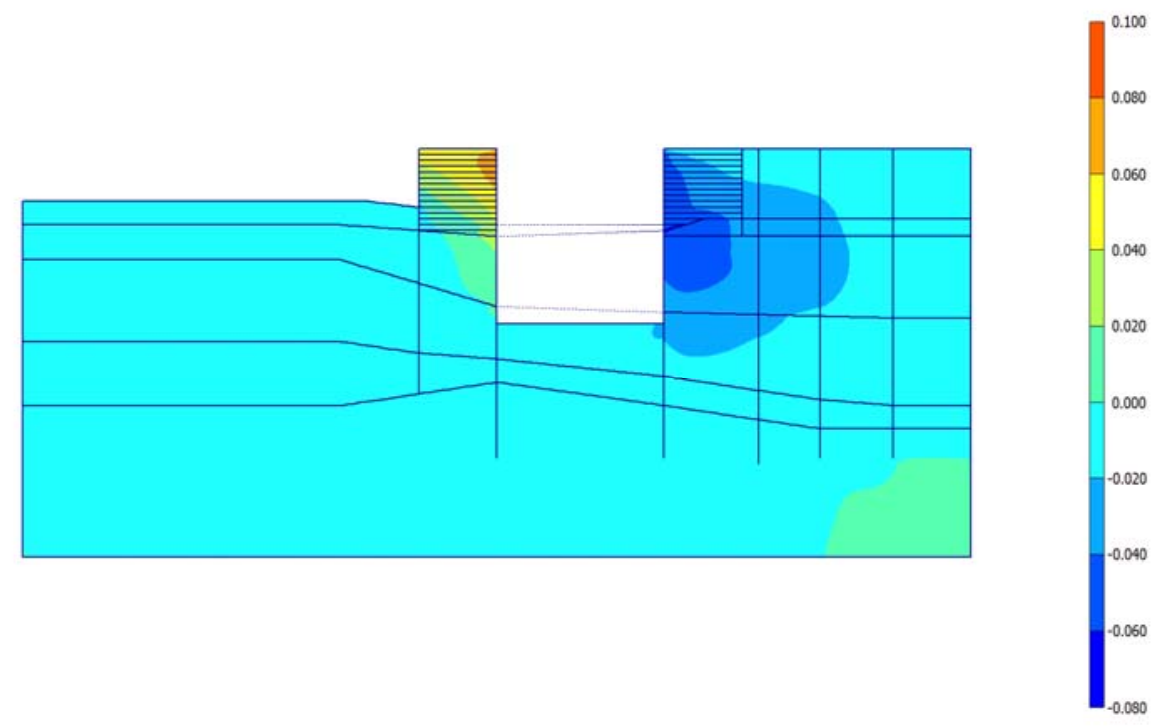

Fig. 18 Plot of horizontal displacements. 


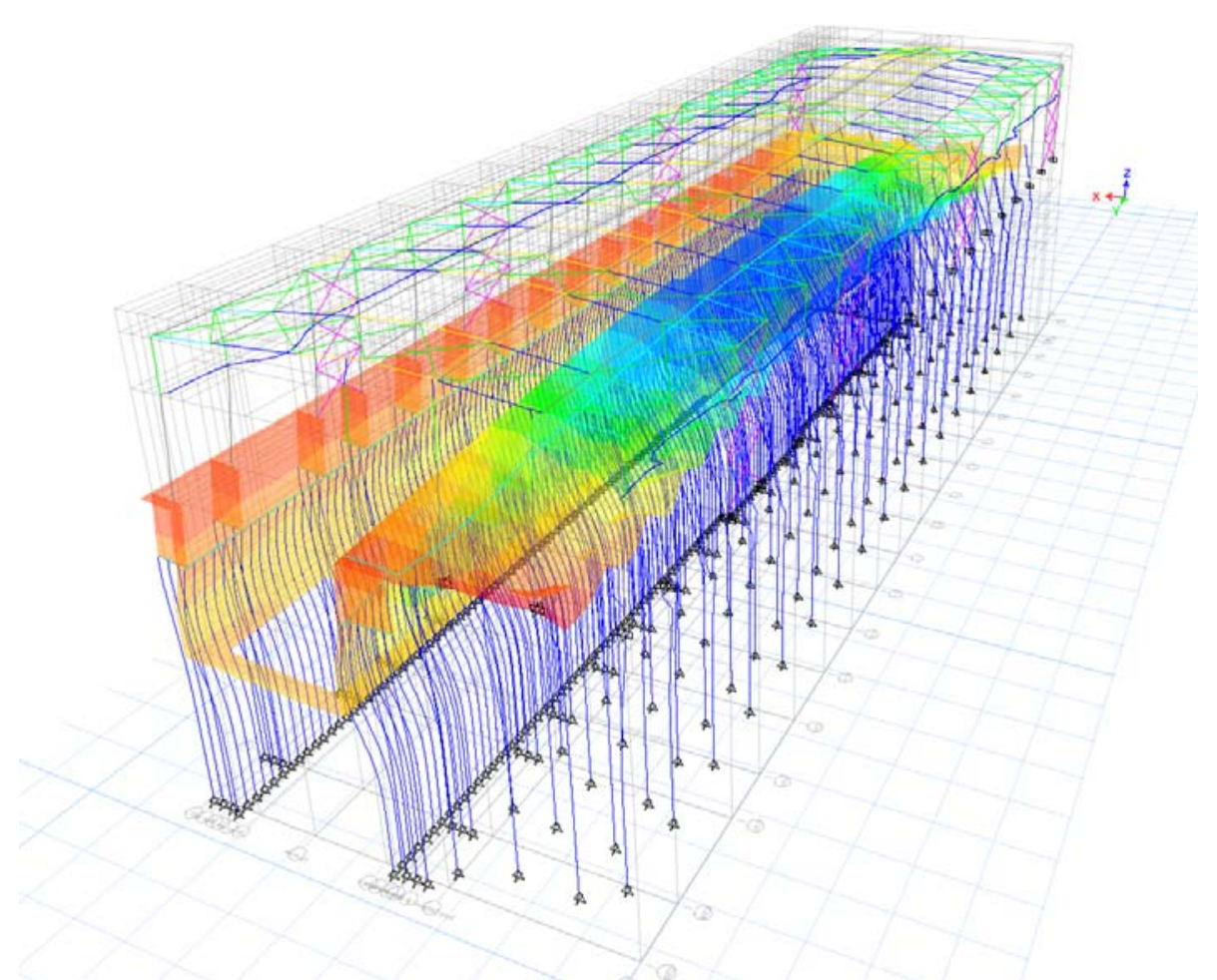

Fig. 19 Three-dimensional representation of the deformed form of the mooring basin and the terminal.

- Wall on the left: $87.5 \mathrm{~mm}$;

- Wall to the right: $46.03 \mathrm{~mm}$.

The design of the retaining walls and the support systems have been carried out using $2 \mathrm{D}$ numerical approaches since the effect of asymmetric loading is considerable; different terrain levels, different ground water levels and different loads on each side of the construction pit leading to props pushing excess force from one side to the other. For ULS analyses FEM have been used and cross checked with subgrade reaction models. In SLS small strain stiffness has been considered in FEM analyses. To ensure that any 3D effects were considered realistically in the 2D models, small 3D FEM models were established and the results were incorporated in the $2 \mathrm{D}$ models.

\subsection{Shore Protection}

The shore protection is located on the property boundary, on the south side, and will connect to the existing banks to the port road on the eastern side.

The shore protection will be achieved through a mixed system of large diameter pilots and protection

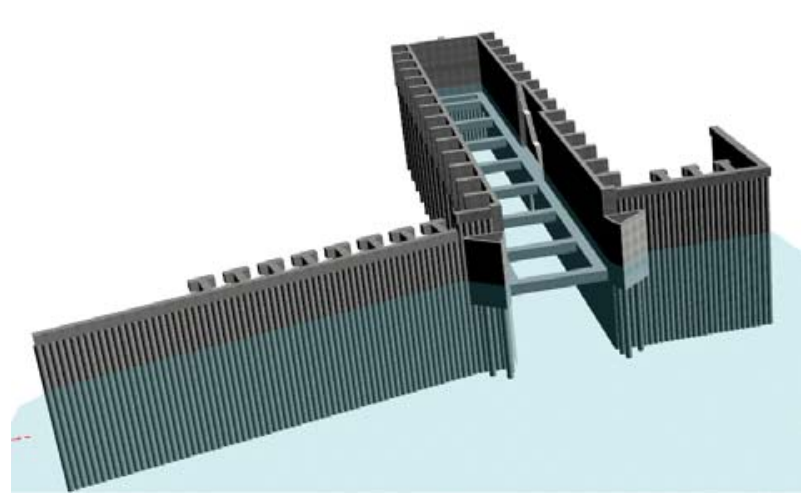

Fig. 20 3D model of the mooring basin.

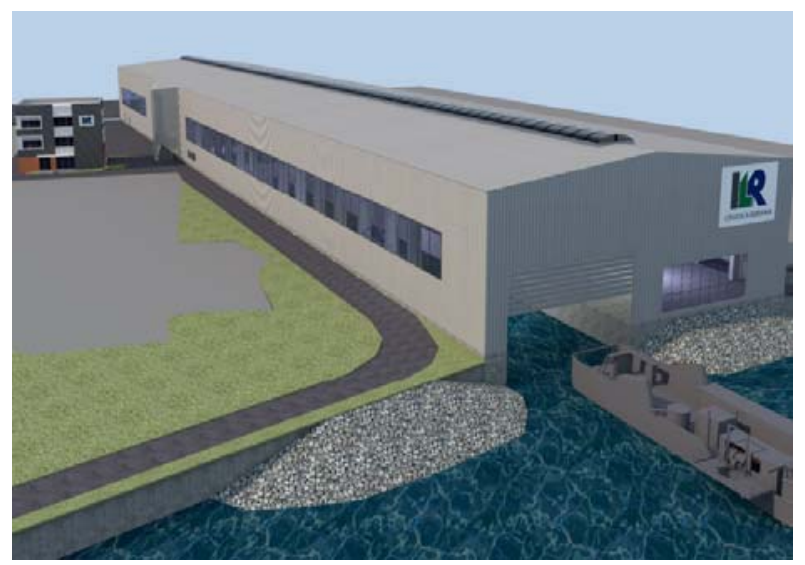

Fig. 21 3D model of the terminal. 


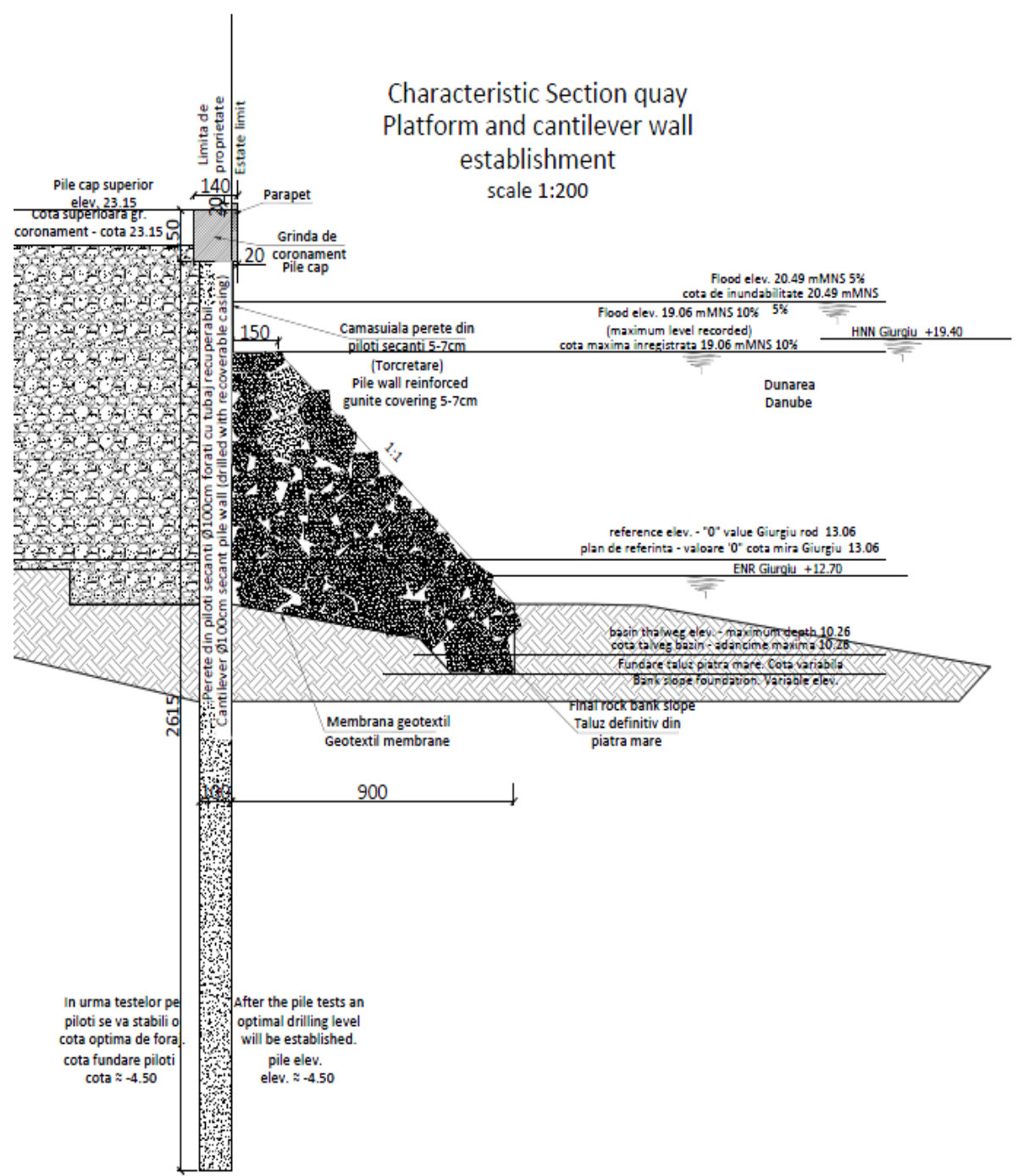

Fig. 22 Shore protection section.

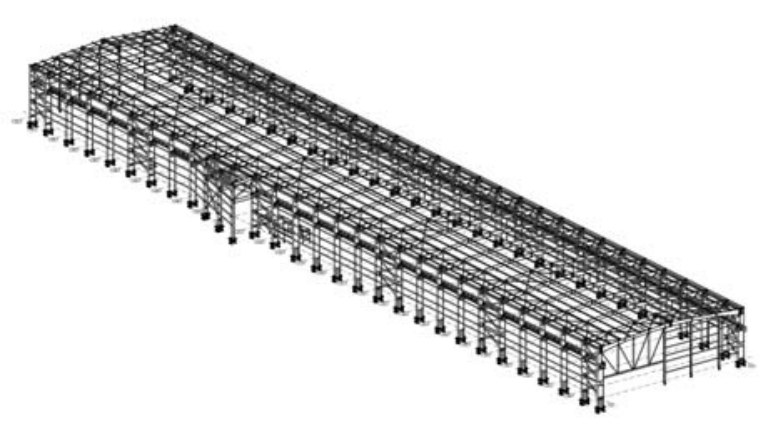

Fig. 23 Superstructures 3D design.

of the segments of the large stone tiller. Coast protection will be achieved over the $21.34 \mathrm{mMNS}$ (probability of $1 \%$ overrun flood level) and a $1 \mathrm{~m}$ guard over this elevation. Coastal protection will have a different structure depending on the conditions imposed by neighbors.

On the eastern side of the site, shore protection will be made of a self-supporting wall made of sectional pile-ups on the exposed face with a reinforced concrete layer.

On the side of the water, shore protection will be mixed, with a sloping sidewall and a large stone pavement.

\subsection{Superstructure}

The structure of the building will be made of metal frames. The metal structure of the warehouse will be made with elements having the section of columnes 
and beams made of welded steel sheets [5].

\section{Conclusion}

Designing and building a port on a river like Danube is always a challenge, considering the associated risks. The characteristic parameters of interaction are numerous and their control difficult. For this reason, the approach of such works should be carefully done during all stages: geotechnical investigation, execution and service. The paper presented a case study for a deep excavation in Giurgiu area required for the construction of the "High Performance Green Port Giurgiu", which was approached according to the Eurocode 7. The work was classified as in geotechnical category no. 3, which imposed a complex approach also from geotechnical investigation, as from design point of view. The execution was permanently monitored and the measurements were compared with the analysis results, allowing a rapid intervention if the real behavior would be different from the estimated one.

\section{Acknowledgment}

The support of Dr. Ramiro Sofronie, $P h D$ and $D H C$ of the Technical University for Civil Engineering in Bucharest, Romania, for preparing the paper submitted to the Journal of Geological Resource and Engineering in New York is gratefully acknowledged.

\section{References}

[1] Sofronie, R., Cazamir, R.-C., Lungu, S., and Gruia, L.-C. 2019. "Danubian Port Giurgiu is Thriving." Proceedings of the 7th Structural Engineers World Congress. Architecture and Structures: From Past to Future. April 24-26, 2019, Istanbul, Turkey.

[2] Iwasaki, Y., and Fukuda, M. 2018. Preservation of the Main Tower of Bayon Temple, Angkor, Cambodia in Geotechnics and Heritage: Historic Towers (edited by Lancellotta, R., Flora, A., and Viggiani, C.). London: Taylor \& Francis Group. ISBN 978-1-138-03272-9.

[3] Landau, L., and Lifchitz, E. 1967. Théorie de L'Élasticité. Moscou: Éditions Mir.

[4] Sofronie, R. 2017. "On the Seismic Jerk." Journal of Geological Resource and Engineering 4: 147-52.

[5] Robertson, E. L. 2017. The Structure of Design. Singapore: The Monacelli Press. 